\title{
La vida social de los precios \\ Evaluaciones monetarias y acción económica en los mercados de la seguridad privada
}

\author{
The social life of prices \\ Monetary assessments and economic action in private security markets
}

Federico Lorenc Valcarce*

\begin{abstract}
Resumo: A partir de un estudio sobre los mercados de la seguridad privada en Argentina, el presente artículo aborda la manera en que los precios son producidos, percibidos, interpretados y manipulados en el curso de las acciones económicas de diversos agentes, así como las estrategias se despliegan para controlar la competencia y el intercambio. Mi trabajo se apoya sobre unas treinta entrevistas con dirigentes de empresas de seguridad y unas cuarenta entrevistas con diversos clientes de esas empresas, además de observaciones realizadas en unas veinte empresas del sector e intercambios informales con informantes clave. Además, me sirvo de materiales producidos por organismos públicos, por cámaras y entidades profesionales del ámbito de la seguridad, y por las propias empresas. En el desarrollo del trabajo, muestro que los precios son negociados en el curso de las transacciones mercantiles y que los actores introducen otros principios de interacción que la competencia para tratar de asegurar la rentabilidad de sus empresas o la calidad de los productos que compran.
\end{abstract}

Palabras clave: Seguridad privada; Competencia; Precios; Intercambio; Consumo

Abstract: Based on a study of private security markets in Argentina, this paper discusses the way in which prices are produced, perceived, interpreted and manipulated in the course of economic actions of various actors. My work is based on thirty interviews with leaders of security companies and forty interviews with different kinds of customers of these companies, as well as observations made in twenty companies in the sector and informal exchanges with key informants. In addition, I use materials produced by

* Doutor em Ciência Política pela Universidade de Paris 1 Panthéon-Sorbonne. Pesquisador do CONICET no Instituto de Investigaciones Gino Germani da Universidade de Buenos Aires e Professor Adjunto do Departamento de Sociologia da Universidade Nacional de Mar del Plata. Autor de: La sécurité privée en Argentine: entre surveillance et marché (Paris, Karthala, 2010) e La crisis de la politica en Argentina (Buenos Aires, Ediciones de la Flor, 1998).<federico.lorenc@googlemail.com $\geq$.

\begin{tabular}{|l|l|l|l|l|l|}
\hline Civitas & Porto Alegre & v. 10 & n. 3 & p. $450-467$ & set.-dez. 2010 \\
\hline
\end{tabular}


public institutions, chambers and professional organizations in the field of security, and by the companies themselves. In this paper, I show that prices are negotiated in the course of market transactions and that the actors introduce principles of interaction other than competition to ensure the profitability of their businesses or the quality of the products they buy.

Keywords: Private security; Competition; Prices; Exchange; Consumption

Mis investigaciones sobre la construcción social de los mercados de la seguridad privada en Argentina abordan diversos aspectos de la producción, la circulación y el consumo de un tipo particular de servicios ${ }^{1}$ : aquellos que tienen por objeto la vigilancia de personas, lugares y cosas. Pongo allí el acento sobre la delimitación y la definición de las mercancías ofrecidas, el tipo de saber que se vuelca en su producción, la manera en que son comercializadas y el modo en que son apropiadas por distintos grupos sociales (Lorenc Valcarce, 2010). Ahora bien, los aspectos "cualitativos" de las transacciones mercantiles son indisociables de sus aspectos "cuantitativos", en particular de la determinación monetaria del valor de las mercancías: en lo tocante a cantidades y proporciones, el trabajo de campo en el mundo de la vigilancia privada revela la importancia de los precios en la organización de los intercambios. La importancia de los precios en este caso particular reenvía a su vez al problema más general de la construcción social de los precios, la orientación de los agentes con respecto a ellos y los efectos que tienen sobre las relaciones sociales en las que operan.

La economía política clásica afirma que los precios de las mercancías no son propiedades naturales de las cosas o frutos de convenciones sociales, sino la expresión de relaciones entre individuos y grupos. Si seguimos las consecuencias analíticas de este enfoque, llegamos a la idea de que los precios son tanto una expresión de relaciones objetivas entre productores,

\footnotetext{
Que se trate de servicios y no de bienes introduce algunas especificidades en el análisis. De hecho, el servicio no adquiere la exterioridad cosificada que sí tiene el bien, por lo que su objetividad no aparece separada de la actividad vital de los individuos que lo realizan a través de su trabajo. Ahora bien, esta particularidad no impide que algunos servicios sean objeto de transacciones mercantiles, y que por lo tanto sean organizados bajo contratos comerciales y se les fije un precio. En todo caso, nuestro estudio abre el camino para otras aproximaciones a la indagación de los procesos sociales de formación de precios y de organización de transacciones mercantiles, sin suponer que sea posible realizar generalizaciones o establecer un modelo abstracto potencialmente válido para los más variados casos. Por lo tanto, ofrecemos más bien una exploración preliminar que invita a desarrollar nuevas líneas de análisis comparativo de diferentes mercados concretos en el marco de una sociología económica que combine la indagación etnográfica con el trabajo documental y el procesamiento estadístico de diversos materiales (cf. Dufy y Weber, 2009).
} 
intermediarios, consumidores, cámaras empresarias, sindicatos y gobierno, como un principio estructural que se impone a los agentes y fija condiciones a sus prácticas. Entonces, nos veremos llevados a formular preguntas que van más allá del interés ordinario de los economistas: ¿Cuáles son las determinaciones sociales concretas de los precios de las diferentes clases de mercancías? ¿Cómo influyen esos precios, por lo tanto los sistemas de relaciones que ellos expresan, sobre el comportamiento de los agentes? ¿Qué estrategias desarrollan estos agentes para adaptarse a la coerción de los valores de cambio? No puedo ofrecer aquí una respuesta general a estas interrogaciones. No obstante, procuraré desarrollar algunos acercamientos parciales a partir del estudio del caso particular de los mercados de la seguridad privada en Argentina: me apoyaré en entrevistas con productores y consumidores de estos servicios, para detectar la manera en que los precios aparecen como elementos significativos de sus sistemas especializados de prácticas mercantiles.

En el presente trabajo propongo analizar la manera en que los precios son producidos y el modo en que afectan las acciones económicas de los diversos agentes, determinando el lugar que cabe a este principio de organización de las transacciones y describiendo las estrategias que los actores despliegan para controlar la competencia y el intercambio. En los primeros apartados, indago los procesos de formación de precios en un sistema de interacciones complejas que reúne a empresas y consumidores, pero también a cámaras empresarias e instancias estatales, y considero los efectos diferenciales que esos precios tienen en las prácticas económicas y en los intercambios mercantiles de los diferentes agentes. Luego, presento las principales estrategias utilizadas por las empresas para evitar la competencia en precios y ensamblar transacciones comerciales en función de principios como la localización, la especialización y la fidelización. Esto permite observar la manera en que los agentes se orientan por los precios, tanto para convertirlos en parámetro de sus elecciones como para evitar que ello suceda y organizar sus comportamientos en función de otros criterios.

\section{El precio como voluntad y representación}

En un marco de análisis sociológico, el precio no es sólo una variable económica. Es fundamentalmente un hecho social. Más allá de las "leyes" que contribuyen a su formación, sabemos que es una medida socialmente producida, que se presenta de maneras diversas a los actores y tiene efectos diferenciados sobre sus comportamientos.

Desde el punto de vista del productor, el precio aparece como la función de sus costos y de los márgenes de ganancia que desea realizar. En efecto, 
me ha sucedido a menudo que, al preguntar los precios de los productos a los dirigentes de empresa, me hayan ofrecido un esquema de costos y beneficios con el fin de explicarme que ganan poco ("una empresa de seguridad es poco rentable") o que los clientes quieren pagar montos que no permiten cubrir los gastos de reclutamiento, formación, equipamiento y supervisión, ni las obligaciones laborales e impositivas ("la gente quiere comer faisán y pagar por pollo"). Según los responsables de las empresas prestadoras, la estructura manifiesta de los costos de producción de servicios de seguridad presenta tres componentes principales: el trabajo vivo (que incluye el salario de los trabajadores, sumamente importante en el sector de la vigilancia humana, pero también los gastos de reclutamiento y formación); los costos fijos (seguros, equipos, alquileres); los impuestos y aportes sociales. Si a ello agregamos la ganancia del capital, llegamos al precio medio de los servicios ofrecidos. ${ }^{2}$

Pero el precio no es el sólo efecto de la estructura de cada empresa sobre el valor de las mercancías producidas, sino que expresa las relaciones objetivas que ligan a los agentes económicos especializados en la fabricación de bienes o servicios relativamente homogéneos, por lo tanto más o menos intercambiables entre sí. Por su parte, existen condicionamientos fijados por el Estado - salarios mínimos, cargas sociales, impuestos - y otros negociados con los sindicatos - salarios mínimos sectoriales, complementos no remunerativos, cantidad de horas trabajadas. Así, las variaciones de los precios pueden tener su origen en la interacción con los clientes, en la competencia con los pares o en las condiciones impuestas por las instancias políticas.

En el momento de ofrecer un servicio, conversando con el potencial cliente o enviando un presupuesto, los representantes comerciales proponen un precio. Ese "precio de anuncio"3 surge del análisis de los costos y los beneficios deseados, pero es también objeto de una negociación directa con el cliente y de una anticipación del precio que propondrá un competidor. Los

2 En los casos en que se cumplen con las regulaciones acordadas entre el gobierno, el sindicato y las cámaras empresarias del sector, los precios no pueden estar por debajo de cierto umbral. Sin embargo, la informalidad es moneda corriente en la industria de la seguridad. Volveré luego sobre esta cuestión.

3 En su estudio sobre el mercado de pulgas de Saint-Ouen, Hervé Sciardet propone un análisis de los precios en una secuencia temporal en tres momentos: primero, hay un "precio de anuncio" que es la respuesta del vendedor a la pregunta “¿cuánto cuesta eso?” planteada por un comprador cualquiera; luego, está el "precio de mercado" que designa el punto en que varios clientes "están al borde de la decisión de comprar"; finalmente, el "precio de transacción" es aquel en el que se realiza la compraventa. De allí deduce una intuición sociológica muy estimulante: "lo que distingue a los mercados realmente existentes es que los precios deben ser aprendidos" (Sciardet, 2003, p. 120-124). Muchas décadas antes, Maurice Halbwachs afirmaba que los precios son también "recordados", y que para eso la materialidad de las tiendas y las etiquetas adheridas a los productos juegan un papel importante (Halbwachs, 2010). 
vendedores sondean a los potenciales clientes, pero también monitorean la situación del mercado y los precios medios vigentes.

Pero el precio que ofrecen está determinado por las condiciones sociales en las cuales se lleva adelante la actividad económica. En una situación ideal en la que los salarios mínimos y las obligaciones fiscales son respetados, la única variable importante que los empresarios pueden controlar es el volumen de ganancia. Según me explicaron repetidamente mis entrevistados, el servicio de un vigilador cuesta alrededor de 30 pesos la hora, lo que para un servicio de 200 horas mensuales arroja un total de aproximadamente 6.000 pesos. ${ }^{4} \mathrm{El}$ patrón paga 2.700 pesos al trabajador, además debe desembolsar 1.000 pesos de aportes, cargas sociales y seguros. Los costos de administración, supervisión y venta, así como la inversión en instrumentos necesarios para la producción de los servicios (vehículos, combustible, uniformes, armas) representan otros 300 pesos. Deducidos los diferentes impuestos, la renta potencial para el capital es de alrededor de 600 pesos por hombre y por mes. Es sobre ese margen que los empresarios pueden negociar con los clientes. ${ }^{5}$

Ahora bien, los vendedores no son los únicos participantes de una transacción comercial. En la medida de sus conocimientos y su poder de imposición, los clientes tienen la capacidad de buscar, evaluar, seleccionar y condicionar a los prestadores que habrán de ofrecerles el servicio. Desde el punto de vista del cliente, el precio es antes que nada un monto de dinero que debe desembolsar para adquirir un bien o un servicio: en función de diversos elementos que ha de sopesar y jerarquizar, su decisión habrá de orientarse más o menos en función de los precios.

En el caso de la seguridad privada, cuando se trata de clientes residenciales, la relación está sometida a las dinámicas colectivas que se desarrollan en los consejos de administración, en las asambleas de vecinos o simplemente en las familias. En opinión de los prestadores desencantados, esto genera demandas

\footnotetext{
4 Utilizo aquí los valores aproximativos de 2010. La fuerte inflación del periodo 2002-2010 impide hacer cálculos precisos y permanentes. En todo caso, durante todo mi trabajo de campo - y en las entrevistas que sigo realizando cuando se me presenta la oportunidad - los empresarios suelen tomar lápiz y papel para presentarme su versión de la determinación de los precios, que es una cuestión que parece interesarles sobremanera.

5 Estos valores permiten comprender que una parte importante de los empresarios se conforme con dirigir empresas de alrededor de 100 trabajadores: se trata de organizaciones rentables y relativamente fáciles de manejar, "gobernables" como suelen decir ellos mismos, que garantizan unos beneficios mensuales suficientes para situar a sus propietarios en la cúspide de la distribución de ingresos en Argentina. Del mismo modo, los "vigiladores" aceptan salarios relativamente bajos debido a las condiciones formales del empleo (seguridad social, cobertura médica, contrato de trabajo) y a que, tratándose de individuos con calificaciones relativamente bajas, no tienen mejores alternativas en el mercado de trabajo (Lorenc Valcarce y Beccaria, 2006).
} 
contradictorias. Pero, además, estos clientes son "avaros" que quieren tener un servicio de calidad: para ahorrar, los clientes terminan por consumir servicios de mala calidad, o por elegir a los productores que no respetan las normas comerciales, salariales y jurídicas vigentes. Esto baja los niveles de rentabilidad, pero sobre todo resiente la calidad de los servicios.

Como han mostrado numerosos estudios en las más diversas circunstancias, los compradores regatean, desplegando estrategias para lograr una reducción de los precios. En algunos casos observados, el cliente señala al prestador que existe un competidor que ofrece el mismo servicio a menor precio, o bien que brinda más prestaciones por la misma cantidad de dinero. De ese modo, un precio disponible es utilizado estratégicamente para forzar un cambio del precio de la transacción en curso: en algunos casos, no sin frustración, el prestador acepta igualar el precio de su competidor; en otros casos, invoca la fidelidad recíproca en la relación comercial, o bien se cuestiona la calidad del servicio que ofrece su rival o la transparencia en el funcionamiento de la empresa, señalando los riesgos de "solidaridad" que afronta el cliente en caso de contratarlo.

Esto sucede con más frecuencia en el caso de los clientes corporativos que, por el volumen de sus compras o el prestigio de sus marcas, cuentan con mayor poder de imposición. Ciertos tipos de empresas fuerzan a sus prestadores a aceptar un precio inferior al que tiende a operar en el mercado: como en otros rubros en los que utilizan bienes o servicios provistos por contratistas, las cadenas de supermercados, bancos o tiendas de electrodomésticos imponen a las empresas de vigilancia los precios y los plazos de pago que les parecen convenientes, afirmando que "brindar este servicio le dará prestigio". En las licitaciones privadas, las grandes empresas - que suelen contar con un responsable in house que define las necesidades de protección de la organización - simplemente definen los servicios que quieren adquirir en el mercado y colocan a los prestadores en una situación de feroz competencia de precios. Algunos prestadores aceptan brindar el servicio a valores que no aseguran la rentabilidad, pero que pueden ser ajustados paulatinamente en función de diferentes justificaciones (incremento de costos, mejora del servicio, etc.), aprovechando la desaparición de los competidores o especulando con las dificultades que el contratante tiene para disolver el vínculo contractual y volver a lanzar una demanda al mercado.

Este tipo de lógica parece operar también en las contrataciones estatales. En efecto, las organizaciones del sector público suelen adquirir bienes y servicios a través de licitaciones y concursos de precios, en los que la obligación legal es optar por la alternativa más barata ante igualdad de prestaciones. "El Estado es 
un mal comprador que paga precios viles" nos dice con disgusto un pequeño empresario. Este malestar se convierte en protesta escandalizada cuando se observa que las compras se realizan a precios incompatibles con las propias condiciones que el Estado establece a través de la fijación de salarios mínimos, obligaciones de formación y seguros, cargas sociales e impositivas.

\section{El precio es relacional}

A pesar de los condicionamientos que padecen y la impotencia que eso les genera, muchos de los empresarios consideran estas circunstancias como totalmente naturales: "el cliente busca lo más barato y nosotros le ofrecemos lo que quiere" nos dice sin emoción el director de una mediana empresa del sector. La determinación del precio aparece así como un espacio de negociación, incluso como un campo de lucha: cada agente procura imponer un precio favorable a sus intereses, pero no lo logra sino en la medida en que la contraparte acepta, sea por falta de alternativas, sea por un ajuste "a la baja" de sus expectativas. Para que el precio propuesto por clientes más o menos poderosos logre imponerse deben existir vendedores que estén dispuestos a aceptar esta influencia externa y hacerla jugar en el terreno de la competencia, condicionando así a los otros vendedores. En todo caso, los agentes concretos del intercambio se ponen de acuerdo sobre el monto que será avanzado para la compra de un servicio. Esto no resulta simplemente de la voluntad de las dos partes, sino también de determinaciones objetivas que se imponen a unos y otros.

En efecto, ni el precio ofrecido ni el precio demandado son valores absolutos: estos montos son siempre relativos dado que - en un espacio de competencia en el que muchos operadores luchan por apropiarse de las oportunidades de ganancia - cada precio aparece como una magnitud más alta o más baja que la que propone otro vendedor a cambio de un producto que es juzgado como equivalente. Según los testimonios recogidos, la competencia tiende a organizarse en función de los precios, lo que obliga a reducir costos o márgenes de ganancia, cuando no directamente la calidad de las prestaciones y de las condiciones de funcionamiento de la empresa. Ahora bien, todos los agentes tienen estrategias para evitar que la articulación comercial se realice sólo en función de la forma del valor: sea para asegurar la continuidad de un intercambio, sea para garantizarse un servicio de calidad o cierta flexibilidad en los pagos, tanto vendedores como compradores pueden organizar sus transacciones en función de otros principios. A veces esto es resultado de acuerdos más o menos explícitos; en otros casos se trata de circunstancias objetivas socialmente producidas y que se imponen. 
Por consiguiente, los precios se determinan en el intercambio entre vendedores y compradores bajo el influjo de la competencia. El vendedor se constituye como tal en el seno de un sistema de relaciones objetivas entre agentes que luchan por apropiarse de los clientes para, de ese modo, obtener ganancias: cada uno trata de bajar los costos, especializarse, fidelizar a los clientes o producir una imagen de marca con el fin de estabilizar sus transacciones y aumentar sus ingresos globales. Ahora bien, esta relación mercantil y esta lógica competitiva están sometidas a constreñimientos externos, sobre todo los que impone el Estado y las normas que rigen el funcionamiento de la industria. ${ }^{6} \mathrm{~A}$ su turno, los consumidores procuran obtener servicios baratos y de buena calidad, pero están en ello condicionados por la distribución desigual de las oportunidades de compra, por las restricciones presupuestarias, por los condicionamientos de las compañías de seguros, e incluso por los valores y orientaciones ideológicas de los miembros de la organización o del público que frecuenta sus locales. En todos estos casos, se observa que "los precios no hacen todo, el todo hace los precios" (Bourdieu, 2000, p. 240).

Ahora bien, esos precios socialmente producidos en la competencia y el intercambio se presentan luego como "datos objetivos" de la realidad económica que los actores deben tener en cuenta a la hora de orientar su conducta. Sea que se acepte de manera pasiva su carácter ineluctable, sea que se desplieguen estrategias para evitar su imperio, lo cierto es que los operadores orientan sus acciones por la existencia de los precios. Ahora bien, los efectos de los precios no son uniformes y se imponen de manera diferenciada en la experiencia de los agentes en función de la posición que ocupan en el mercado.

\section{Estrategias para evitar las luchas de precios}

La lucha entre vendedores es una competencia por la apropiación de partes del mercado. Hay momentos y lugares donde esa lucha se organiza en torno a los precios; pero existen estrategias típicas y recurrentes que los agentes despliegan activamente para evitar la lucha de precios: por un lado, se buscan nichos a través del enraizamiento espacial y la especialización funcional; por otro lado, se construyen relaciones comerciales estables y se producen símbolos de calidad en vistas de obtener el reconocimiento de los demás productores y de los clientes.

\footnotetext{
6 Por ejemplo, los prestadores insisten sobre las políticas salariales fomentadas por los gobiernos Kirchner e impuestas a las empresas privadas. En el sector de la seguridad privada, los salarios mínimos pasaron de 430 pesos en 2001 a 985 pesos en 2006 y 2.700 pesos en 2010, como resultado de los movimientos generales de la economía formal y los acuerdos particulares entre los sindicatos y cámaras empresariales del sector.
} 
La manera en que un actor participa en el juego de la competencia está determinada por la posición de mercado, es decir, por las relaciones objetivas que lo unen con los demás vendedores y con el universo más o menos indeterminado de los compradores potenciales. En términos generales, es extraño que una empresa de seguridad privada se lance en la competencia abierta. Al contrario, cada empresa busca su propio nicho y se adapta así a la situación (White, 1981; Podolny, Stuart y Hannan, 1996).

Estos nichos se presentan a menudo como "clientes al alcance de la mano" que son relativamente accesibles por el hecho de tener con el productor relaciones que van más allá del intercambio de un servicio por dinero. En otros casos, surgen como consecuencia de la inversión focalizada que los empresarios realizan en cierto espacio geográfico o en determinado tipo de clientes. En todo caso, las empresas ven los mercados en perspectiva: hay áreas geográficas y sectores de actividad que no son accesibles, mientras otros no son siquiera conocidos; hay otras zonas que son más próximas y permeables, ajustándose muchas veces al perfil específico de lo que cada operador tiene para ofrecer. De este modo, las empresas invierten selectivamente sus esfuerzos comerciales y buscan producir y ocupar un nicho - más o menos extenso - que les permitirá mantenerse y desarrollarse. Esta inversión focalizada contribuye a su vez a definir el perfil de la empresa y el tipo de articulación con el entorno, convirtiéndose así en un patrón de reproducción en el tiempo que impone condiciones al mismo tiempo que permite la supervivencia de la organización. Por lo tanto, el mercado no es una arena extendida y homogénea, que se contempla desde lejos y desde fuera, sino más bien un sistema de perspectivas diferenciadas según la posición que cada uno ocupa. Los agentes se esfuerzan, batiéndose en un contexto que no controlan, pero donde es necesario reducir la incertidumbre para poder actuar.

Una primera estrategia de supervivencia es la localización. Cuando se analiza la presencia territorial de las principales empresas de seguridad privada, salta a la vista que ofrecen sus servicios en las regiones más pobladas del país. Algunas tienen incluso un alcance nacional. Al contar con los recursos necesarios, pueden disputar clientes en cualquier mercado. Al contrario, las pequeñas empresas suelen estar confinadas a ciertos barrios o a pequeñas provincias, tanto como a pequeños clientes y a un pequeño número de clientes. En efecto, las empresas ubicadas en las provincias más importantes son también las que tienen más empleados y pueden operar en otras zonas; eso no impide que empresas medianas puedan ser dominantes en espacios más restringidos: si en Buenos Aires las empresas líderes de seguridad privada tienen 4.000, 7.000 y hasta 10.000 empleados, en provincias como Tucumán, 
Mendoza o Córdoba, las empresas dominantes tienen un promedio de 250 empleados, mientras que en las provincias más pequeñas ninguna empresa llega siquiera a los 100 empleados. Existen empresas arraigadas en una ciudad o una localidad - lo que entraña relaciones permanentes y estables con un conjunto de clientes efectivos o potenciales - que pueden poner barreras de entrada tanto a las nuevas empresas que quieran constituirse como a las grandes empresas nacionales que deseen instalarse en su territorio. Estas empresas no luchan por expandirse a nuevos espacios, pero logran impedir que jugadores foráneos penetren en los suyos.

Una segunda estrategia de supervivencia es la especialización. Las empresas de seguridad privada tienden a concentrarse en ciertos rubros o a ofrecer combinaciones particulares de servicios, aun cuando se observa una tendencia creciente a los "servicios integrales", que en parte se pueden brindar gracias a las alianzas y subcontrataciones con otros prestadores, y que tienen por fundamento la demanda de clientes a los que se tiene acceso: en efecto, todo cliente es portador de necesidades que pueden satisfacerse con diferentes prestaciones, pero la elección del prestador suele basarse en la confianza. Las grandes empresas de seguridad tienden a combinar todo tipo de servicios vigilancia y protección, monitoreo electrónico y óptico, custodias móviles, consultoría, etc. - que se ofrecen de manera individual o combinada. A medida que descendemos hacia las empresas medianas o pequeñas, se observan dos alternativas organizacionales que corresponden a dos maneras de enfrentar los desafíos de la competencia: o bien las empresas se especializan en un tipo de servicio, como ser vigilancia, instalación y monitoreo de alarmas, $\mathrm{u}$ otro, o bien se especializan en un tipo de cliente, como ser consorcios, empresas de transportes o fábricas. En todo caso, se trata de reducir el campo de acción para poder concentrar los esfuerzos y obtener rendimientos a partir de la especificación de los intercambios.

\section{La producción y el mantenimiento de una clientela}

Como se observa en estos dos casos, la configuración de los servicios ofrecidos y los patrones de localización dependen en gran medida de las relaciones con los clientes, reales o potenciales. En efecto, las prestaciones ofrecidas y los lugares de radicación dependen parcialmente de las oportunidades de negocios que las empresas encuentran en el mercado. Así, las empresas que brindan servicios de seguridad a empresas industriales de zonas rurales ofrecen al mismo tiempo servicios de mantenimiento de jardines y piscinas, incluso de protección de campos y maquinarias agrícolas. En el mismo sentido, las empresas especializadas en pequeños clientes urbanos - 
sobre todo condominios y locales comerciales - han recurrido pronto a los sistemas de alarmas y cámaras de video, mucho más baratos, lo que les permitió expandirse luego hacia clientes aun más modestos. Todo parece mostrar que las oportunidades ofrecidas por los primeros clientes determinan la dirección y los límites de la diversificación de las prestaciones: los servicios ofrecidos se organizan en función de la situación objetiva de los consumidores.

Pero debe señalarse que esta adaptación a las necesidades de los clientes no es algo pasivo, como si se tratase de una determinación directa y mecánica. Al contrario, la producción de una clientela, luego su conservación, son tareas fundamentales de una empresa: como me repetían a menudo los empresarios, "sin cliente no hay actividad". Y, de hecho, tener una clientela es una de las formas típicas de evitar la incertidumbre que acarrea la competencia.

En las primeras etapas de una empresa, el trabajo de conseguir clientes se realiza sobre todo a partir del esfuerzo de los fundadores: se trata de movilizar las redes de contactos disponibles para tratar de convertir esos vínculos en relaciones comerciales. Además, se debe marcar la presencia en el terreno, darse a conocer, construir un nombre propio.

Una vez que la empresa se ha establecido y dispone de una clientela, se pone en marcha un circuito de reproducción y expansión, un "círculo virtuoso" cuyo funcionamiento ya no se controla totalmente: la clientela se convierte en un capital del que las empresas disponen para hacer nuevos clientes. Según los testimonios de todos los empresarios entrevistados, el principal mecanismo de expansión de la clientela es la "referencia", la información que circula "de boca en boca". Este mecanismo es a veces puesto en marcha por los propios clientes, más allá de la voluntad y de la intervención de los prestadores.

En efecto, los clientes también utilizan sus propias redes de relaciones para evaluar los servicios que ofrecen profesionales y empresas, tanto en el mercado de la seguridad privada como en otros (Geertz, 1978; Di Maggio y Louch, 1998). Tanto los clientes particulares como los responsables corporativos consultan con familiares, amigos o colegas, escuchan las referencias que ofrecen personas en situación análoga, reciben información sobre la reputación de las empresas y la calidad de los servicios prestados. Lo único que pueden hacer los proveedores es afianzar su reputación sobre la base de un trato adecuado y una prestación de calidad.

En resumen, las acciones de vendedores y compradores hacen que la competencia que observamos en los mercados de la seguridad no sea ni una lucha impersonal entre firmas aisladas que se disputan clientes desconocidos, ni un mero ajuste de las transacciones en función de los precios. Al contrario, se trata de un espacio estructurado por medio de estrategias diversas de enlazamiento 
que contribuyen a estabilizar las transacciones, a minimizar los riesgos, a generar redes de intercambio que estructuran relaciones mercantiles.

\section{Precios, poder y confianza en las relaciones de intercambio}

Ahora bien, estas relaciones mercantiles tienen una historia y una estructura: existe una recurrencia de los intercambios que contribuye a reproducir el modo de organización de los mercados. En efecto, una vez que se establecen los lazos entre productores y consumidores, la concurrencia tiende a atenuarse. Si están satisfechos con los servicios recibidos, los compradores ahora convertidos en clientes no cambiarán de proveedor.

En efecto, la fidelización es un tipo de relación comercial durable que conviene tanto al vendedor como al comprador. Gracias a este mecanismo, las transacciones no son actos aislados sino elementos de una cadena que se prolonga en el tiempo y que existe gracias a la voluntad de los contratantes: unos realizan previsiones sobre el volumen de su producción y planean sus actividades de acuerdo a ello, los otros procuran obtener un servicio personalizado y con calidad garantizada. El consumidor ahorra así los costos de búsqueda de información y de evaluación que debería realizar cada vez que desea comprar un bien o un servicio, mientras que el productor reduce la incertidumbre de sus operaciones y evita eventuales costos de inventario o de mano de obra ociosa (Granovetter, 1993, p. 35-37).

Ahora bien, esta fidelización - que no es más que una forma de "clientelismo" o particularismo en la esfera mercantil - puede ser más o menos simétrica. Según diversos testimonios, las grandes empresas y los organismos estatales tienen cada vez más poder a la hora de definir los servicios que adquieren, pero también para determinar el precio que pagan por ellos. En la medida en que se generaliza el mecanismo de llamado a licitación, los compradores definen de antemano las características de las prestaciones: los oferentes deben adecuarse a estos requisitos y, manteniendo constante este factor, la elección se realiza en función del precio. De este modo, el prestador debe demostrar su capacidad de brindar el servicio en las condiciones propuestas por el comprador, pero debe también proponer un precio que esté por debajo del que fijarán sus competidores. Esto es una fuente de incertidumbre, pero existen también maneras de manejarla: por un lado, "se sabe" quiénes han de presentarse a la licitación o se conocen las redes de contactos que los responsables de la contratación tienen en la industria de la seguridad; por otro lado, se busca información acerca de los "precios de mercado" (Sciardet, 2003), consultando con colegas, clientes frecuentes y otros "informantes". Anticipar el "precio de transacción" (Sciardet, 2003) es un objetivo que se 
persigue a través de un trabajo minucioso y sistemático. A veces, esto se logra por medio de tareas de inteligencia, en otros casos por colusión pura y directa con los encargados de la compra. Son las relaciones sociales las que permiten reducir la incertidumbre y soldar el lazo mercantil.

En términos generales, la capacidad de imponer condiciones en una transacción mercantil depende del poder relativo del vendedor y del comprador. Los testimonios de los actores y el análisis de la estructura de los mercados revelan que la seguridad privada se ha alejado en los últimos años del modelo de "mercado de vendedores", en el que los productores pueden imponen los bienes y servicios que quieran al precio que más les convenga, a un "mercado de compradores" en el que los clientes pueden - gracias a la experiencia acumulada, al volumen y la frecuencia de sus compras, y a la proliferación de prestadores que ofrecen el mismo tipo de servicios - imponer sus condiciones al proveedor (Baker, Faulkner y Fisher, 1998).

\section{Tiempo, precios y vínculos comerciales}

Hay así una temporalidad global de los mercados de la seguridad privada que pone en evidencia dos modalidades sucesivas y opuestas de existencia de los precios: en las primeras etapas, las transacciones estaban completamente encastradas en solidaridades personales, la oferta era restringida y las empresas tenían una contabilidad flexible; pero la expansión de la oferta, la consiguiente intensificación de la competencia, y las exigencias de los clientes han transformado la manera en que los precios organizan las actividades y las relaciones. En este proceso general, tanto como en cada transacción particular, el tiempo cuenta.

En efecto, si los precios tienden a la baja a medida que los mercados de la seguridad se institucionalizan, la configuración inversa se observa en la trayectoria individual de las empresas, sobre todo de aquellas que aparecen desde los años 1990. Ante una situación de competencia cada vez más intensa, las empresas debutantes venden a bajo precio para atraer a los clientes; esto constituye una amenaza potencial para los jugadores establecidos. Pero a medida que una empresa se consolida y alcanza un volumen de negocios suficiente para asegurar su rentabilidad, las estrategias comerciales se transforman. Así, prefieren limitar su crecimiento, sobre todo si eso implica mantener los precios bajos, establecer relaciones con clientes problemáticos (los que no pagan, piden siempre más o se quejan permanentemente) o hacer una inversión demasiado elevada en mano de obra y equipos para asegurar una prestación que no garantiza un vínculo contractual estable: “¿Qué hago si debo contratar 300 empleados para asegurar un servicio y quince días 
antes del vencimiento del contrato me dicen que no me lo renuevan?" es una cuestión que ejemplifica el razonamiento utilizado frecuentemente para justificar las estrategias conservadoras de muchos empresarios medianos y pequeños.

Cuando un recién llegado ofrece servicios baratos que ponen en riesgo el capital de clientela de una empresa, los actores ya establecidos responden hablando otro lenguaje que el del puro cálculo económico, el dinero y los precios: conversando con el cliente que podría llegar a alejarse, se subrayan las ventajas de una relación durable basada en la confianza y el conocimiento mutuo. Es cierto que el prestador puede ponerse de acuerdo con el cliente para bajar los precios y reconducir el vínculo comercial: pero este mecanismo tiene un límite y los empresarios están cada vez menos dispuestos a utilizarlo, sobre todo cuando ello entraña la pérdida completa de la rentabilidad. Es más frecuente que el propietario, el director o el responsable comercial discutan con el cliente en términos más generales: el vendedor amenazado insiste sobre la trayectoria, la presencia en el mercado y la fiabilidad de la empresa, o bien sobre la historia de la relación comercial en común, y la incertidumbre que introduce un cambio de prestador; puede insistir sobre aspectos técnicos como la responsabilidad fiscal y legal, los seguros obligatorios, la formación del personal y todos los elementos que pudiesen significar un riesgo legal para el comprador, o bien un servicio de menor calidad. Si ello no resultare suficiente, porque el precio que el cliente está dispuesto a pagar para seguir comprando el servicio es demasiado bajo, el vendedor puede abandonar sus intentos y dejar caer el contrato.

En el otro polo, los clientes contribuyen también a la estabilización de las transacciones. En efecto, si están satisfechos con el servicio recibido, y las diferencias de precios no son enormes, prefieren persistir en su primer vínculo: pueden utilizar la presencia de una alternativa como recurso para negociar con su propio prestador, pero la opción por "lo ya conocido" parece constituir la regla. Cuando las diferencias de precios son grandes y los argumentos extraeconómicos no alcanzan para convencer al cliente, pueden aparecer otras soluciones alternativas. Una de las más frecuentes es el abaratamiento de los precios gracias a la sustitución de servicios de vigilancia humana por dispositivos electrónicos: de este modo, la innovación tecnológica aparece como una solución al problema de la competencia mediante la sustitución de la prestación por un equivalente menos costoso. Pero también puede ocurrir que un cliente cambie de prestador. En algunos casos, esto condena a una empresa a la desaparición. De hecho, la mortalidad de las empresas es relativamente elevada en la industria de la seguridad privada. 
En este marco de búsqueda de nichos, fidelización, información e imposición de la propia voluntad, los precios aparecen como un elemento más de la acción económica: en la medida en que las estrategias de los agentes se transforman, se transforma también el modo de orientación con respecto al precio. Pero, en todo caso, vemos claramente que los precios no son propiedades de las cosas. Son la expresión monetaria de una relación social que implica la participación de vendedores y compradores, pero también la eficacia de un marco político, cultural e institucional en el cual se constituyen los mercados.

\section{Conclusión}

En la práctica, los agentes reales de los mercados concretos despliegan estrategias para escapar de la tiranía de la determinación cuantitativa del valor: los competidores se ponen a veces de acuerdo sobre ciertos principios de interacción, incluso se reparten el mercado según cuotas negociadas, o buscan ocupar nichos protegidos para evitar la competencia. Por el otro lado, construyen lazos de confianza y lealtad con los clientes, para impedir así que estos se vean confrontados a situaciones de verdadera elección. Sea bajo la forma de un "mercado" estabilizado o de una "jerarquía" oculta, las transacciones no operan en el vacío, sino que están siempre enraizadas en redes de intercambio más amplias entre individuos y grupos.

Sin embargo, en un marco de creciente competencia, la coerción de los precios se hace más fuerte. Ahora bien, esta coerción no es contradictoria con la idea de que las relaciones mercantiles están encastradas en redes sociales, marcos culturales o instituciones políticas. Se trata de dos modalidades que operan, sea en ámbitos diferenciados, sea como dos lógicas en tensión en una misma relación de intercambio. En todo caso, las transacciones no se dejan gobernar completamente por las leyes económicas: están condicionadas por los precios, por la determinación monetaria del valor, pero también por criterios sentimentales (amistad, confianza), funcionales (previsibilidad, interdependencia controlada) o políticos (alianzas, clientelismo, regulaciones estatales).

Así, los precios son el subproducto de un sistema de relaciones sociales de producción y de circulación de bienes y servicios: "los precios en dinero son producto de lucha y compromiso; por tanto, resultados de una constelación de poder" (Weber, 1992, p. 82). Las relaciones de poder entre los diferentes actores y las estrategias que utilizan para realizar sus intereses tienen efectos sobre los precios. La búsqueda de relaciones de confianza con la clientela tiende justamente a evitar la competencia en precios, que favorece ya a los 
grandes operadores, ya a quienes trasgreden las reglas de juego y optan por la informalidad.

Podría pensarse que los mercados de la seguridad constituyen un caso singular y que, por lo tanto, nada de lo que allí se observe puede servir como punto de partida para una generalización teórica. Sin embargo, otras investigaciones muestran que este enraizamiento de las relaciones mercantiles no es propio de un sector particular de la economía. Las relaciones entre vendedores y compradores suelen apoyarse en relaciones personales o lealtades entre organizaciones: los clientes pueden tener tendencia a dirigirse siempre al mismo proveedor (Di Maggio y Louch, 1998; Plattner, 1983), y los productores suelen sentirse más seguros cuando conocen la situación económica y los atributos morales del cliente (Uzzi y Lancaster, 2003; 2004). En algunos sectores, como la construcción, la industria textil o el comercio minorista, las grandes empresas suelen establecer relaciones permanentes con pequeños contratistas que les proveen bienes y servicios (Stinchbombe, 1959; Eccles, 1981; Perrow, 1993; Lazerson, 1993). Los vendedores de los mercados y ferias al aire libre organizan sus acciones en vistas de fidelizar a su clientela y no buscan siempre maximizar el beneficio de corto plazo (Plattner, 1982; Sciardet, 2003). Las firmas establecen lazos privilegiados con sus bancos o con sus agencias de publicidad para asegurarse un servicio de calidad (Baker, 1990; Baker, Faulkner y Fisher, 1998). Por otra parte, los vínculos mercantiles no se agotan en una transacción instantánea y se inscriben en una temporalidad particular: la duración de las relaciones comerciales es en gran medida el resultado de las orientaciones y de las estrategias de agentes que producen conexiones de mercado para garantizar el buen funcionamiento de sus organizaciones (Baker, 1990, p. 618). Todo esto tiene consecuencia sobre los precios: los vínculos personales y la interacción continua entre ciertos agentes hacen que los intercambios no se celebren según las condiciones que fijaría una situación general de equilibrio (Granovetter, 2005).

En síntesis, el estudio de los mercados de la seguridad privada revela lo que ya ha sido señalado en muchos trabajos de sociología y antropología económica: los mercados no son meros sistemas de transacciones económicas, sino también realidades sociales, políticas y culturales. Sin embargo, los precios no han sido considerados hasta aquí en los mismos términos: suele concederse que constituyen verdaderos principios objetivos de los intercambios mercantiles, datos de una realidad que no puede deconstruirse. En ese sentido, nuestro trabajo ha procurado explorar algunas pistas en torno a "la vida social de los precios", para tratar de mostrar que estas determinaciones cuantitativas del valor de los objetos son producidas, modeladas, interpretadas 
e incorporadas por los agentes, que de ese modo contribuyen a hacerlas existir como realidades económicas.

\section{Referencias}

BAKER, Wayne. Market networks and corporate behavior. American journal of sociology, Chicago, v. 96, n. 3, p. 589-625, nov. 1990.

BAKER, Wayne; FAULKNER, Robert; FISHER, Gene. Hazards of the market: the continuity and dissolution of interorganizational market relationships. American sociological review, Nashville, v. 63, n. 2, p. 147-177, abr. 1998.

BOURDIEU, Pierre. Les structures sociales de l'économie. Paris: Seuil, 2000.

DI MAGGIO, Paul; LOUCH, Hugh. Socially embedded consumer transactions: for what kinds of purchases do people use networks most? American sociological review, Nashville, v. 63, n. 5, p. 619-37, out. 1998.

DUFY, Caroline; WEBER, Florence. Más allá de la gran división: sociología, economía y etnografía. Buenos Aires: Antropofagia, 2009.

ECCLES, Robert. Bureaucratic versus craft administration: the relationship of market structure to the construction firm. Administrative science quarterly, Ithaca, v. 26, n. 3 , p. 449-469, set. 1981.

GEERTZ, Clifford. The bazaar economy: information and search in peasant marketing. American economy review, Nashville, v. 68, n. 2, p. 28-32, maio 1978.

GRANOVETTER, Mark. The impact of social structure on economic outcomes. Journal of economic perspectives, Pittsburgh, v. 19, n. 1, p. 33-50, jan. 2005.

GRANOVETTER, Mark. The nature of economic relationships. In: SWEDBERG, Richard (Org.). Explorations in economic sociology. New York: Russel Sage Foundation, 1993. p. 3-41.

HALBWACHS, Maurice. La memoria colectiva. Buenos Aires: Miño y Dávila, 2010.

LAZERSON, Mark. Future alternatives of work reflected in the past: putting-out production in Modena. In: SWEDBERG, Richard (Org.). Explorations in economic sociology. New York: Russel Sage Foundation, 1993. p. 403-427.

LORENC VALCARCE, Federico. La sécurité privée en Argentine: entre surveillance et marché. Paris: Karthala, 2010.

LORENC VALCARCE, Federico; BECCARIA, Alejandra. Transformaciones sociopolíticas y mercado de trabajo: el caso de la seguridad privada en Argentina. Estudios del trabajo, Buenos Aires, n. 31, p. 53-77, dez. 2006.

PERROW, Charles. Small firms networks. In: SWEDBERG, Richard (Org.). Explorations in economic sociology. New York: Russel Sage Foundation, 1993. p. 377-402.

PLATTNER, Stuart. Economic custom in a competitive marketplace. American anthropologist, Arlington, v. 85, n. 4, p. 848-858, dez. 1983.

PLATTNER, Stuart. Economic decision making in a public marketplace. American ethnologist, Davis, v. 9, n. 2, p. 399-420, maio 1982. 
PODOLNY, Joel; STUART, Toby; HANNAN, Michael. Networks, knowledge, and niches: competition in the worldwide semiconductor industry, 1984-1991. American journal of sociology, Chicago, v. 102, n. 3, p. 659-689, nov. 1996.

SCIARDET, Hervé. Les marchands de l'aube: ethnographie et théorie du commerce aux Puces de Saint-Ouen. Paris: Economica, 2003.

STINCHCOMBE, Arthur. Bureaucratic and craft administrations of production: a comparative study. Administrative science quarterly, Ithaca, v. 4, n. 2, p. 168-187, set. 1959 .

UZZI, Brian; LANCASTER, Ryon. Embeddedness and price formation in the corporate law market. American sociological review, Nashville, v. 69, n. 3, p. 319-344, jun. 2004.

UZZI, Brian; LANCASTER, Ryon. Relational embeddedness and learning: the case of bank loan managers and their clients. Management science, Hanover, v. 49, n. 3, p. 383-399, abr. 2003.

WEBER, Max. Economía y sociedad: esbozo de sociología comprensiva. Madrid: Fondo de Cultura Económica, 1992.

WHITE, Harrison. Where do markets come from? American journal of sociology, Chicago, v. 87, n. 3, p. 517-547, nov. 1981. 